\title{
An In Vivo Comparative Evaluation of Postoperative Complications in Single- versus Multiple-Visit Endodontic Therapy: 18-Month Follow-Up
}

\author{
Vivek Joshi ${ }^{1} \quad$ Yogesh Kumar $^{1} \quad$ Neetu Jindal ${ }^{1} \quad$ Renu Aggarwal ${ }^{1}$ \\ ${ }^{1}$ Department of Conservative Dentistry and Endodontics, Surendera \\ Dental College and Research Institute, Sri Ganganagar, Rajasthan, India \\ Address for correspondence Vivek Joshi, MDS, 167 Mansa Devi Nagar, \\ Phagwara 144401, Punjab, India (e-mail: vivekjoshi@gmail.com).
}

Dent J Adv Stud 2019;7:66-73

\begin{abstract}
Keywords

- calcium hydroxide

- single- versus multi-

ple-visit endodontics

- postoperative pain

- periapical rarefaction

Objective The goal of root canal therapy is thorough disinfection and obturation of the root canal system in all its dimensions. Success of endodontic treatment is highly related to the elimination of postendodontic pain, tenderness, and swelling. Single-visit endodontic therapy has several advantages such as increased patient acceptance, less overhead costs, and only single time local anesthesia administration is required. Multiple-visit endodontic (MVE) treatment allows the clinician to determine the effect of the therapy on the inflamed tissues and shorter appointments. This in vivo study was undertaken to compare the postoperative incidence of pain, swelling, tenderness, and radiographic evaluation of periapical pathology following single- versus multiple-visit endodontic therapy in vital as well as nonvital teeth.

Materials and Methods A total of 60 subjects in the age group of 15 to 50 years were selected for the study. The patients were divided into four groups:

- Group $1(n=15)$ : Single-visit endodontic (SVE) therapy with vital pulp involvement without periapical rarefaction.

- Group $2(n=15)$ : SVE therapy of asymptomatic pulpless teeth with periapical rarefaction as observed in radiographic evaluation.

- Group $3(n=15)$ : MVE of vital pulp involvement without periapical rarefactions.

- Group $4(n=15)$ : MVE therapy of asymptomatic pulpless teeth with periapical rarefaction as observed radiographically.

Access cavity was prepared, working length was taken. Biomechanical preparation was done with Protaper universal rotary file system and obturation was done immediately in single-visit cases. In multivisit cases, $\mathrm{Ca}(\mathrm{OH})_{2}$ is placed as an intracanal medicament and obturation was done with the help of $\mathrm{AH}$ plus sealer and gutta-percha. Postobturation pain levels, swelling, and tenderness on percussion were assessed till 6 weeks. The radiographic parameter was studied till 18 months follow-up.

Results Among the different experimental groups, maximum patients in MVE without periapical rarefaction showed no pain according to visual analog scale (VAS) scale, swelling, and tenderness and in SVE with periapical rarefaction showed maximum number of patients reported with pain, tenderness, and swelling. At 4 and 6 weeks postoperatively, patients in all the groups exhibited no pain, swelling, and tenderness to percussion. As periapical rarefaction, healing of periapical lesion was evident in all the patients after 18 months.
\end{abstract}

received

July 20, 2019

accepted

July 27, 2019

published online

November 1, 2019
DOI https://doi.org/

10.1055/s-0039-1697208

ISSN 2321-1482.
(C)2019 Bhojia Dental College and

Hospital affiliated to Himachal

Pradesh University
License terms

() $\odot \circledast$ 


\section{Introduction}

The goal of root canal therapy is thorough disinfection and obturation of root canal system in all its dimensions. ${ }^{1}$ It is believed that the remaining bacteria can be eliminated or prevented by introducing an interappointment dressing such as calcium hydroxide in the root canal. ${ }^{2}$

Success of endodontic treatment is highly related to the elimination of postendodontic pain. There are certain preoperative, interoperative, and postoperative factors which influences the progression of postoperative pain, due to mechanical and chemical irritation of periodontal ligaments, inflammation of tissue adjacent to root canal treated tooth, hyper-occlusion, crack, defective or postendodontic restoration. ${ }^{3}$

Single-visit endodontic therapy has several advantages such as increased patient acceptance, single appointment procedure, less overhead costs, and only single time local anesthesia administration is required. Multiple-visit endodontic (MVE) treatment allows the clinician to determine the effect of the therapy on the inflamed tissues and shorter initial visit for the emergency patient.

Recent studies have shown little or no difference in quality of treatment, incidence of post treatment complications or success rate between single-visit and multiple-visit root canal therapy.

\section{Materials and Methods}

A total of 60 single rooted maxillary central incisors of adult patients requiring root canal therapy were treated in the present in vivo study.

The armamentarium and material used are presented in -Figs. 1 and 2.

\section{Inclusion Criteria}

- The patient should freely accept the proposed single- or multiple-visit treatment.

- Only maxillary central incisors were selected for this study.

- Vital and nonvital teeth were included.

- Teeth in which initial apical master file binds at the apex was of ISO size \#45 or less.

\section{Exclusion Criteria}

- Patient with any systemic disease.

- Pregnant patient.

- Patient who had been taking antibiotics, nonsteroids, anti-inflammatory drugs, or corticosteroids.

- Patient of age below 15 and above 50 years.

- Patient with acute apical periodontitis, acute apical abscess, and weeping canals.

- Necrotic painful teeth with sinus tract.

- Retreatment.

- Teeth with calcified canal.

- Teeth with periapical radiolucencies of diameter greater than $0.5 \mathrm{~cm}(5 \mathrm{~mm})$.

\section{Method}

The patients were divided into four groups:

- Group $1(n=15)$ : Single-visit endodontic therapy with vital pulp involvement without periapical rarefaction.

- Group $2(n=15)$ : Single-visit endodontic therapy of asymptomatic pulpless teeth with periapical rarefaction as observed in radiographic evaluation.

- Group $3(n=15)$ : MVE therapy of vital pulp involvement without periapical rarefactions.

- Group 4( $n=15)$ :MVE therapy of asymptomatic pulpless teeth with periapical rarefaction as observed radiographically.

Only the patients in Groups 1 and 3 were administered with local anesthesia (Lignox 2\% A 1:80,000 adrenaline). Access to the pulp chamber was gained with the Endo Access Bur (Dentsply Maillefer, Ballaigues, Switzerland), then pulp was extirpated using ISO size 20 Barbed Broach (Dentsply Maillefer, Ballaigues, Switzerland; - Fig. 3). Working length was determined by using Coltene Canal Pro Apex locator (Altstatten, Switzerland) and then radiographically with \#15 K file (Dentsply Maillefer, Ballaigues, Switzerland) using digital photostimulable phosphors plates (PSP) method. Root canals were cleaned and shaped by Rotary NiTi ProTaper system (Dentsply Maillefer, Ballaigues, Switzerland) along with use of 17\% EDTA (RC-Prep, Premier dental, Pennsylvania, United States). The root canals were copiously irrigated with $2.5 \%$ sodium hypochlorite (Organo Biotech Laboratories Pvt. Ltd, India). Normal saline was used for final irrigation of root canal to flush out irrigants and debris. Intracanal medicament was used in Groups 3 and 4.

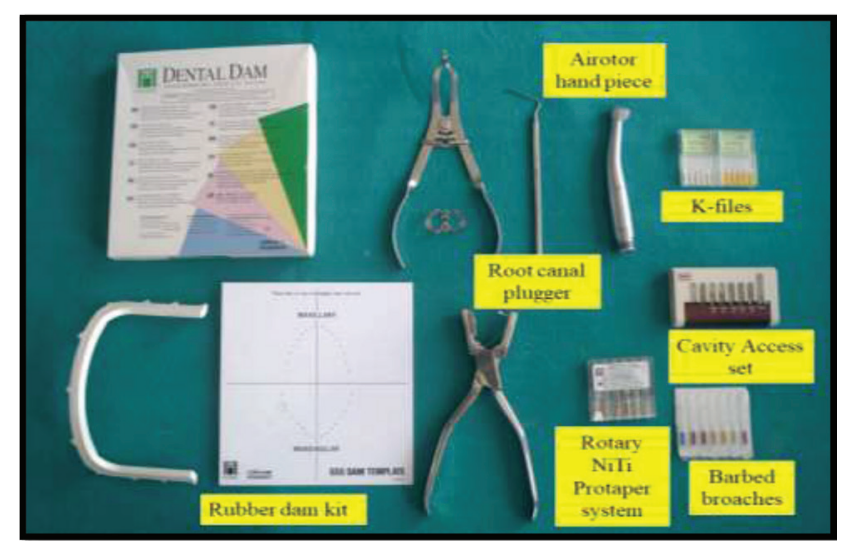

Fig. 1 Armamentarium.

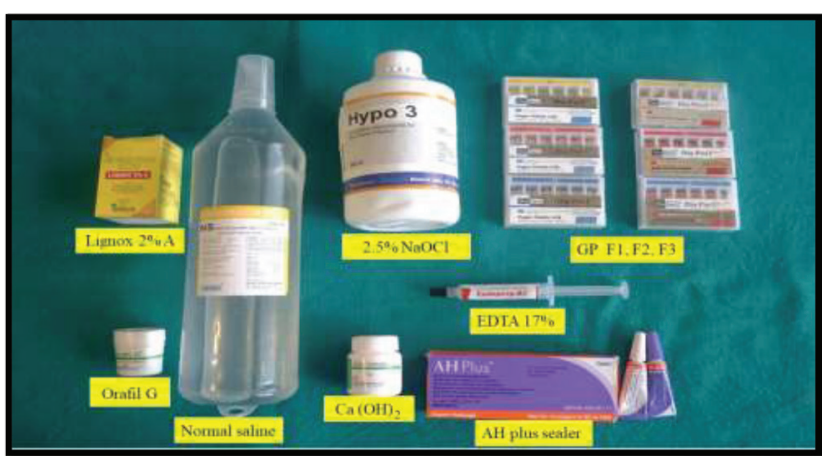

Fig. 2 Materials used. 


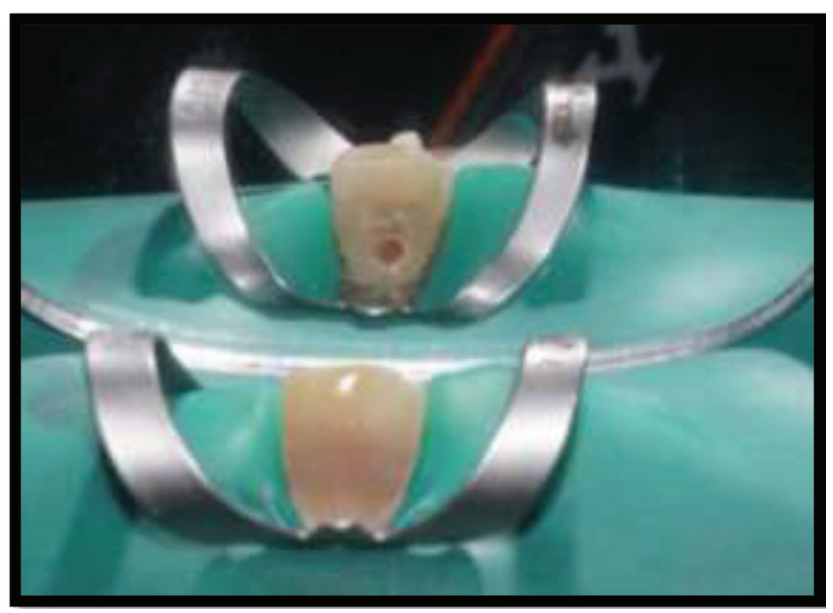

Fig. 3 Isolation with rubber dam.

The root canals were dried with sterile absorbent paper points and obturated with selected master gutta-percha cone using AH-plus sealer (Dentsply Maillefer, Ballaigues, Switzerland) in the same visit but in case of groups 3 and 4; obturation was done in second visit after 1 week.

Vertical compaction was done using the heated plugger (GDC, India) at the canal orifice. Finally, coronal portion was sealed with temporary material Prevest Orafil G (Triodent Meditech India Pvt. Limited, India).

Patients were recalled after 48 hours, 1 week, 4 weeks, and 6 weeks for clinical evaluation of pain, tenderness to percussion, swelling, and after 1.5, 3, 6, 9, 12, and 18 months for periapical radiolucency (- Table $\mathbf{1}$ ).

In all the cases postendodontic restoration was done 6 weeks after the obturation using nanohybrid composite resin material (Ivoclar Vivadent, Liechtenstein).

Postobturation pain levels were assessed using visual analog scale (-Fig. 4). Pain was recorded as no pain, distressing pain, and unbearable pain as appropriate. Swelling was recorded as absent or present. Tenderness to percussion was assessed as being absent or present.

Digital calibration method using Digora software was used for linear measurement of any periapical radiolucency.

The outcome was recorded as favorable, uncertain, or unfavorable. The outcome was adjusted as favorable when postoperatively there was absence of pain, swelling, and radiological evidence of normal periodontal ligament around the root.

The outcome was uncertain if radiographs revealed that a lesion remained the same size or diminished in size. All the calculations were subjected to statistical analysis using Chi-square test.

\section{Results}

\section{Results for Pain}

- At 48 hours postoperatively among the different experimental groups, maximum 12 patients in Group 3, 11 patients in Group 1, 10 patients in Group 4, and 5 patients in Group 2 showed no pain according to VAS scale (-Fig. 5).
- At 1 week postoperatively, 13 patients in Group 1 and Group 3 both exhibited no pain according to VAS scale followed by 12 patients in Group 4, and 9 patients in Group 2.

- At 4 and 6 weeks postoperatively, patients in all the groups exhibited no pain.

\section{Results for Swelling}

- The swelling in 15 patients was absent in Group 3 and Group 1, 1 patient in Group 4 and Group 2 showed presence of swelling at 48 hours postendodontic therapy (-Fig. 6).

- After 1, 4, and 6 weeks, swelling was absent in all the groups.

\section{Results for Tenderness}

- The tenderness at 48 hours was observed in 2 patients in Group 3 and 3 patients in Group 1, 8 patients in Group 2, and 6 patients in Group 4 reported with tenderness on percussion (-Fig. 7)

- At 1 week after the endodontic therapy, no tenderness was present in 15 patients in Group 3. Only 2 patients in Group 1 showed presence of tenderness whereas Group 4 had 3 patients and Group 2 had 4 patients which exhibited tenderness on percussion.

- At 4 and 6 weeks after the endodontic therapy tenderness to percussion was absent in all the groups.

\section{Results of Radiographic Evaluation}

A total of 10 patients in Group 2 and 11 patients in Group 4 showed complete resolution of periapical lesion but 5 patients in Group 2 and 4 patients in Group 4 showed uncertain healing after 18 months follow up (-Fig. 8, - Table 2).

\section{Discussion}

Root canal treatment aims to eliminate bacteria from the infected root canal system to create an environment that is most favorable for healing. Several studies have shown that it is impossible to achieve a bacteria free root canal space in all cases, even after thorough cleaning, shaping, and irrigation with disinfectants or antiseptics. They may multiply rapidly, in some cases, to almost the initial numbers in 2 to 4 days, if the canal is left empty. ${ }^{4}$

Teeth that do not exhibit apical radiolucencies, or sensitivity to percussion or palpation must be assumed to be free of apical inflammation and to have noninfected root canals, single-visit endodontics appears to be the treatment of choice in these teeth, assuming that instrumentation and obturation are performed aseptically. ${ }^{5}$

Periapical pathology evolves as a response to microorganisms present in the root canal. Consequently, endodontic treatment tries to eradicate the microbes from the root canal system to promote periapical healing. ${ }^{6}$

This present in vivo study was done to compare and evaluate postoperative incidence of pain, swelling, tenderness, and radiographic evaluation following single- versus 
Table 1 Comparison of Postendodontic complications (pain, swelling, and tenderness) in single- versus multiple-visit endodontic treatment

\begin{tabular}{|c|c|c|c|c|c|c|c|c|c|}
\hline Parameter & $\begin{array}{l}\text { Time } \\
\text { period }\end{array}$ & Scale & Group 1 & Group 2 & Group 3 & Group 4 & Chi-value & $p$-Value & Status \\
\hline \multirow[t]{12}{*}{ Pain } & \multirow[t]{3}{*}{$48 \mathrm{~h}$} & No pain (0) & 11 & 5 & 12 & 10 & \multirow[t]{3}{*}{16.16} & \multirow[t]{3}{*}{0.0129} & \multirow[t]{3}{*}{ SIG } \\
\hline & & $\begin{array}{l}1-5 \text { Distressing } \\
\text { pain }\end{array}$ & 4 & 6 & 3 & 5 & & & \\
\hline & & $\begin{array}{l}\text { 6-10 Unbearable } \\
\text { pain }\end{array}$ & 0 & 4 & 0 & 0 & & & \\
\hline & \multirow[t]{3}{*}{$1 \mathrm{wk}$} & No pain (0) & 13 & 9 & 13 & 12 & \multirow[t]{3}{*}{4.22} & \multirow[t]{3}{*}{0.6469} & \multirow[t]{3}{*}{ NS } \\
\hline & & $\begin{array}{l}1-5 \text { Distressing } \\
\text { pain }\end{array}$ & 2 & 6 & 2 & 3 & & & \\
\hline & & $\begin{array}{l}6-10 \text { Unbearable } \\
\text { pain }\end{array}$ & 0 & 0 & 0 & 0 & & & \\
\hline & \multirow[t]{3}{*}{4 wk } & No pain (0) & 15 & 15 & 15 & 15 & \multirow[t]{3}{*}{0} & \multirow[t]{3}{*}{1} & \multirow[t]{3}{*}{ NS } \\
\hline & & $\begin{array}{l}1-5 \text { Distressing } \\
\text { pain }\end{array}$ & 0 & 0 & 0 & 0 & & & \\
\hline & & $\begin{array}{l}6-10 \text { Unbearable } \\
\text { pain }\end{array}$ & 0 & 0 & 0 & 0 & & & \\
\hline & \multirow[t]{3}{*}{6 wk } & No pain (0) & 15 & 15 & 15 & 15 & \multirow[t]{3}{*}{0} & \multirow[t]{3}{*}{1} & \multirow[t]{3}{*}{ NS } \\
\hline & & $\begin{array}{l}1-5 \text { Distressing } \\
\text { pain }\end{array}$ & 0 & 0 & 0 & 0 & & & \\
\hline & & $\begin{array}{l}\text { 6-10 Unbearable } \\
\text { pain }\end{array}$ & 0 & 0 & 0 & 0 & & & \\
\hline \multirow[t]{8}{*}{ Swelling } & \multirow[t]{2}{*}{$48 \mathrm{~h}$} & Present & 0 & 1 & 0 & 1 & \multirow[t]{2}{*}{2.07} & \multirow[t]{2}{*}{0.558} & \multirow[t]{2}{*}{ NS } \\
\hline & & Absent & 15 & 14 & 15 & 14 & & & \\
\hline & \multirow[t]{2}{*}{$1 \mathrm{wk}$} & Present & 0 & 0 & 0 & 0 & \multirow[t]{2}{*}{0} & \multirow[t]{2}{*}{1} & \multirow[t]{2}{*}{ NS } \\
\hline & & Absent & 15 & 15 & 15 & 13 & & & \\
\hline & \multirow[t]{2}{*}{4 wk } & Present & 0 & 0 & 0 & 0 & \multirow[t]{2}{*}{0} & \multirow[t]{2}{*}{1} & \multirow[t]{2}{*}{ NS } \\
\hline & & Absent & 15 & 15 & 15 & 15 & & & \\
\hline & $6 \mathrm{wk}$ & Present & 0 & 0 & 0 & 0 & 0 & 1 & NS \\
\hline & & Absent & 15 & 15 & 15 & 15 & & & \\
\hline Tenderness & $48 \mathrm{~h}$ & Present & 3 & 8 & 2 & 6 & 7.012 & 0.072 & NS \\
\hline & & Absent & 12 & 7 & 13 & 9 & & & \\
\hline & $1 \mathrm{wk}$ & Present & 2 & 4 & 0 & 3 & 4.58 & 0.2053 & NS \\
\hline & & Absent & 13 & 11 & 15 & 12 & & & \\
\hline & $4 \mathrm{wk}$ & Present & 0 & 0 & 0 & 0 & 0 & 1 & NS \\
\hline & & Absent & 15 & 15 & 15 & 15 & & & \\
\hline & $6 \mathrm{wk}$ & Present & 0 & 0 & 0 & 0 & 0 & 1 & NS \\
\hline & & Absent & 15 & 15 & 15 & 15 & & & \\
\hline
\end{tabular}

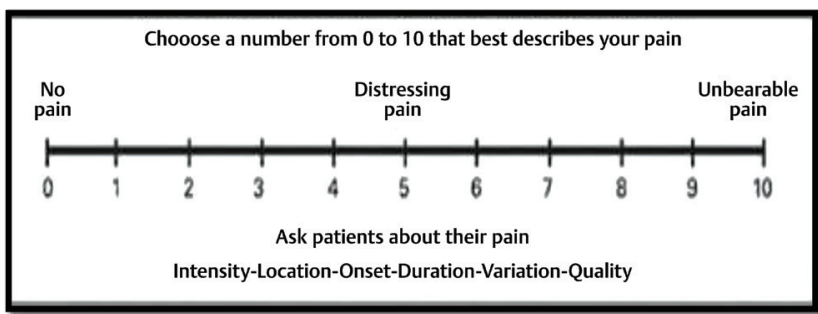

Fig. 4 Visual analog scale. multiple-visit endodontic therapy in vital as well as nonvital teeth.

\section{Pain after 48 Hours}

Group 3 > Group $1>$ Group $4>$ Group 2.

The reasons for postobturation pain after 48 hours are any preoperative symptoms, incomplete removal pulp tissue, and obturation (density). ${ }^{3}$ 


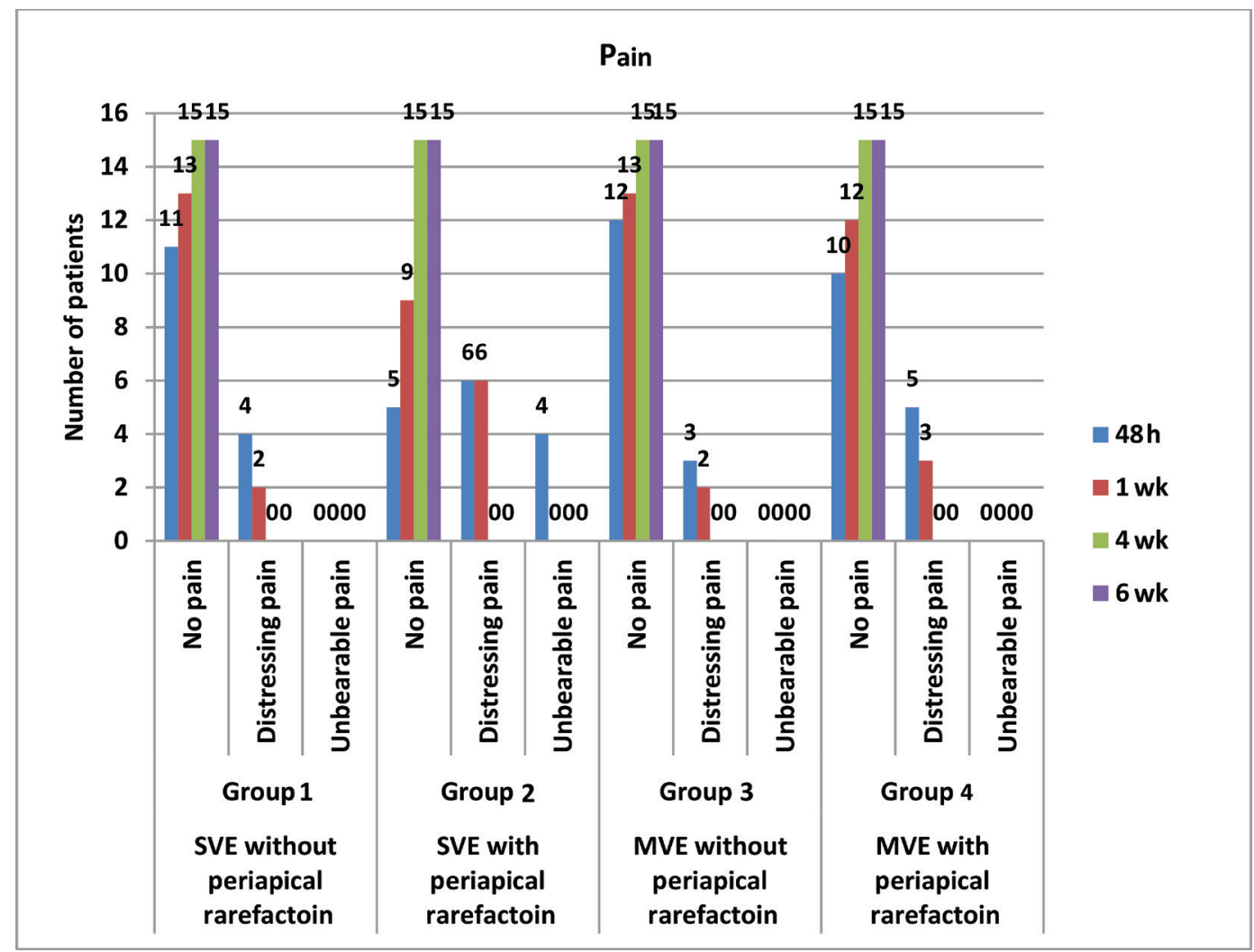

Fig. 5 Intergroup comparison of pain at different time intervals.

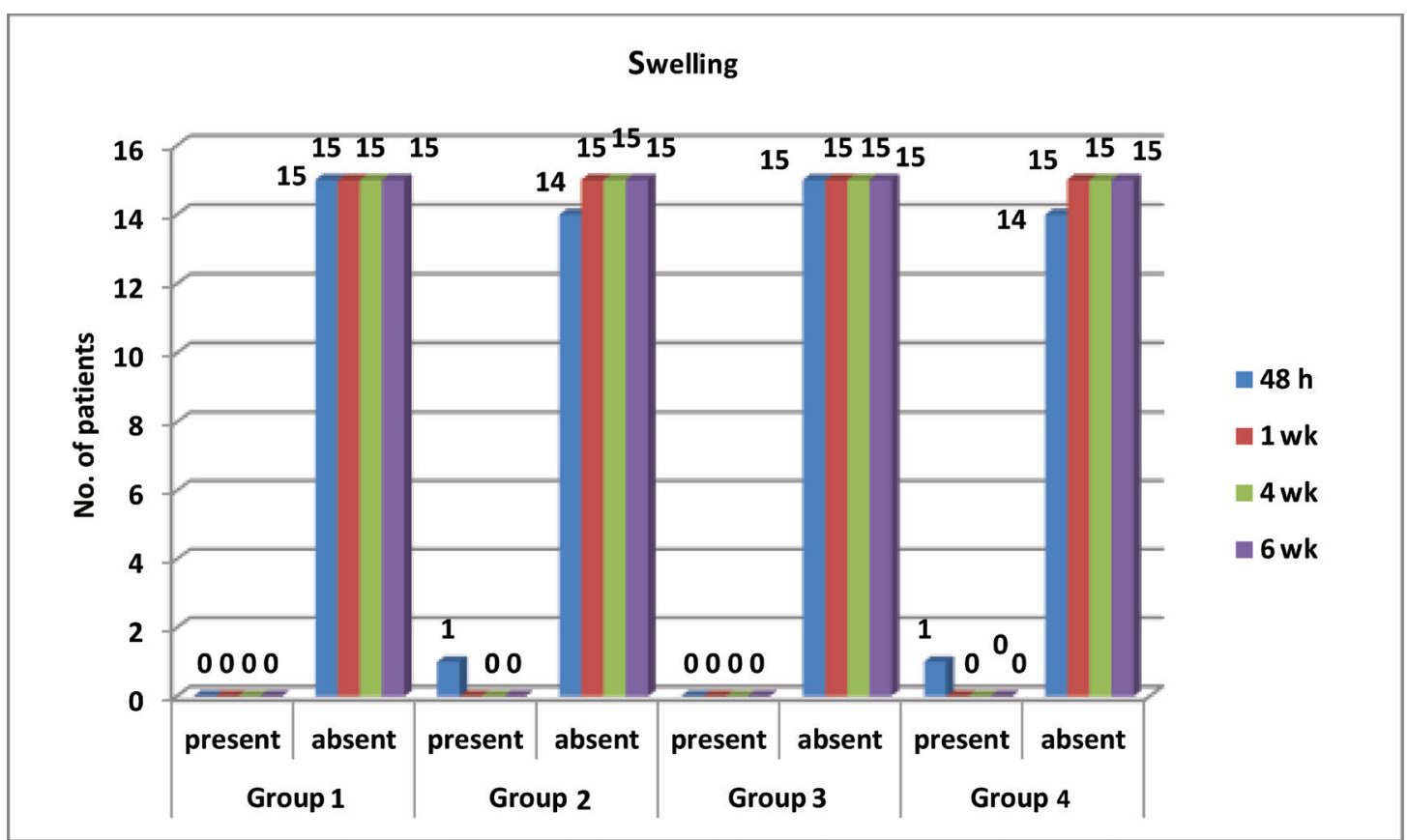

Fig. 6 Intergroup comparison of swelling at different time intervals.

The low incidence of postoperative pain is in agreement with the results of a previous clinical study done by Favain 1992. The antimicrobial activity of calcium hydroxide is related to the release of hydroxyl ions in an aqueous environment. In vitro experiments showed that a 24 -hour contact period is required for complete killing of enterococci. ${ }^{8}$
According to Souza et al, the anti-inflammatory action of calcium hydroxide is generated by different mechanisms; (1) hygroscopic action, directly related to the absorption of the inflammatory exudate by the paste itself; (2) phospholipase inhibition by calcium hydroxide, thus decreasing cellular lysis and subsequently, the liberation 


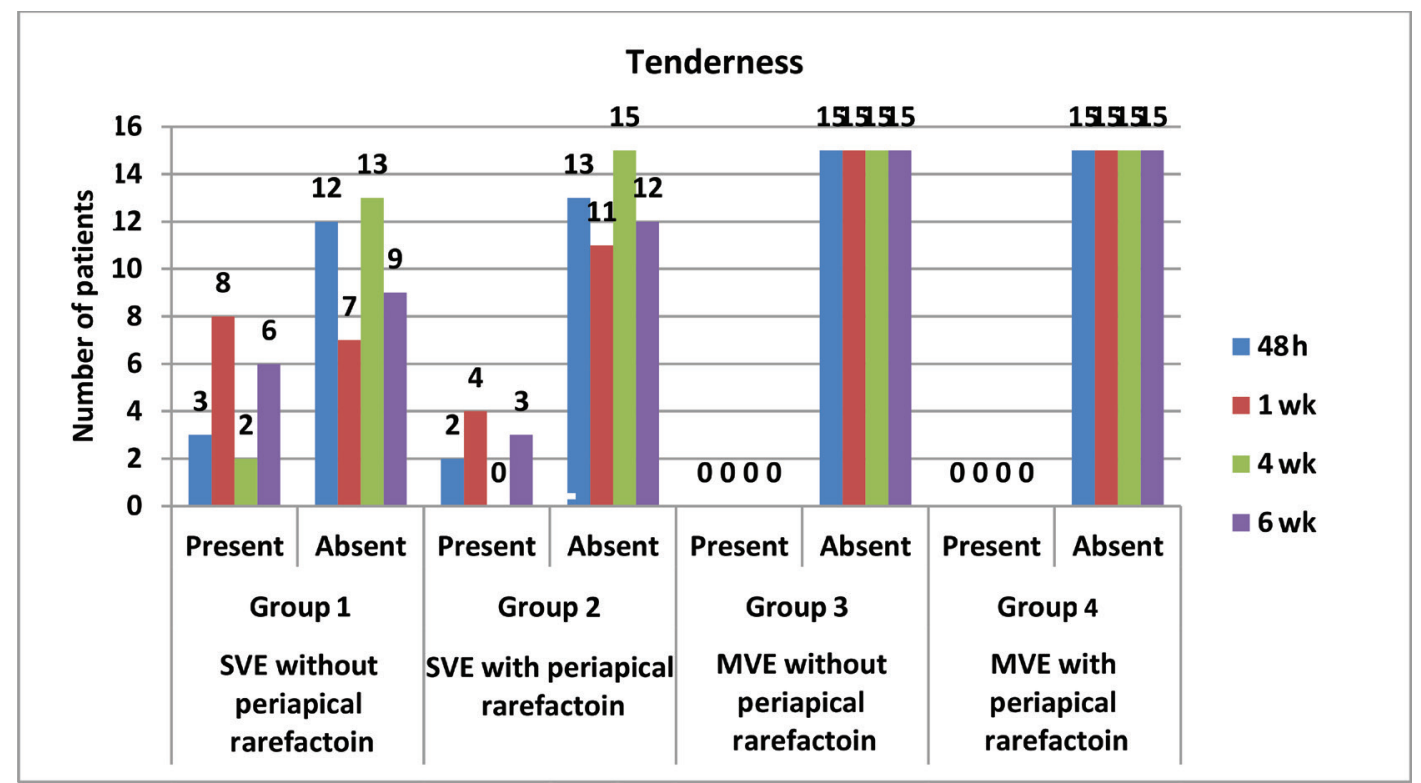

Fig. 7 Intergroup comparison of tenderness at different time intervals.

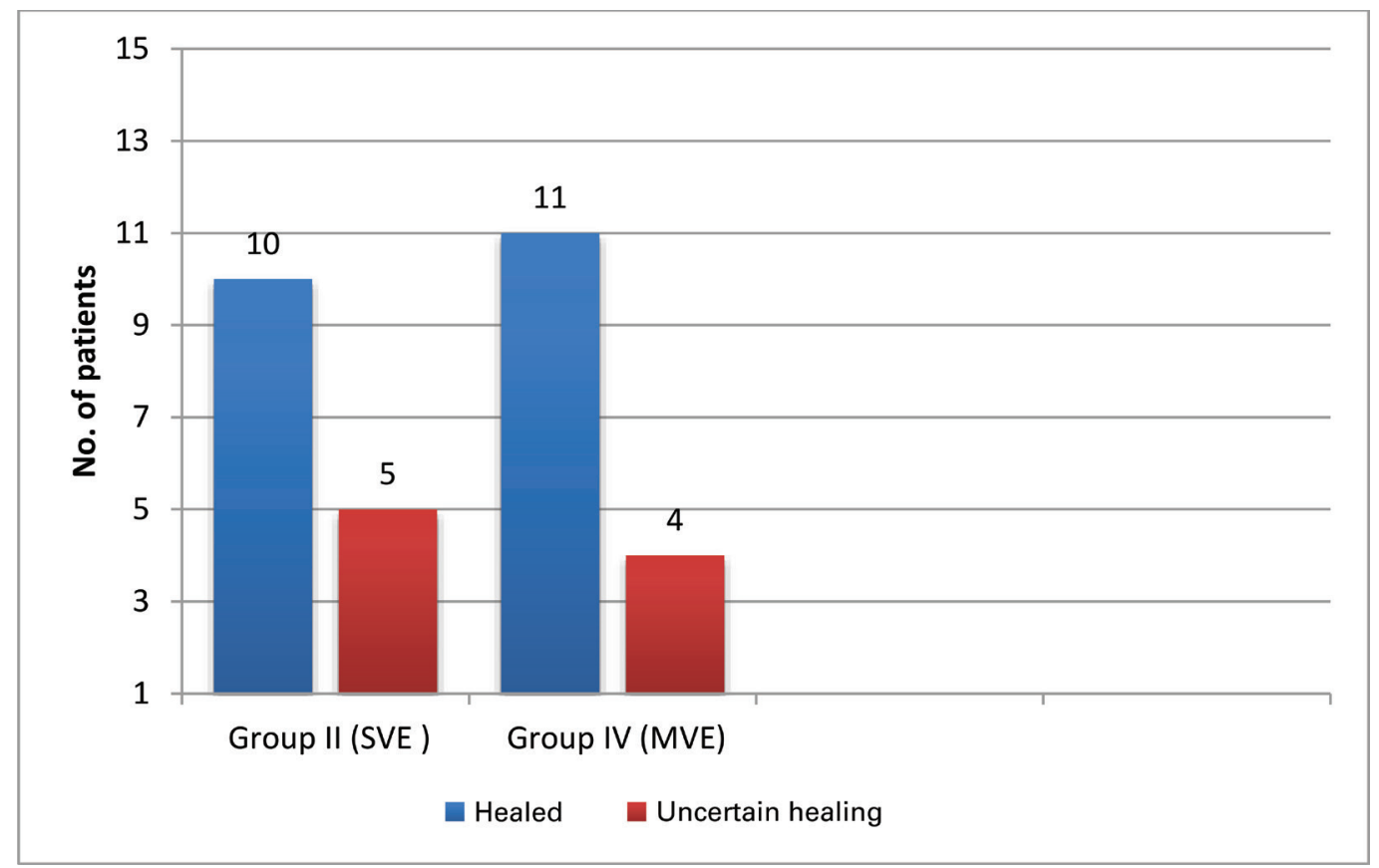

Fig. 8 Intergroup comparison of Group 2 and Group 4 for radiographic evaluation.

Table 2 Intergroup comparison of Group 2 and Group 4 for radiographic finding

\begin{tabular}{|l|l|l|c|c|l|}
\hline & Group 2 & Group 4 & Chi-value & $p$-Value & Status \\
\cline { 1 - 2 } Healed & 10 & 11 & & & \\
\cline { 1 - 2 } & 5 & 4 & 0.25 & 0.8825 & NS \\
\hline
\end{tabular}

of prostaglandins, one of the mediators of inflammation. ${ }^{8}$

In addition to killing bacteria, calcium hydroxide has ability to hydrolyze the lipid moiety of bacterial lipopolysaccharide (LPS), thereby inactivating the biologic activity of LPS and reducing its effect. ${ }^{9}$
However, studies by Molander et al have shown that calcium hydroxide is not always effective and that its action is unreliable. ${ }^{10}$

In 1983, Fava introduced the double-flared technique as an alternative method for root canal preparation of nonvital 
single rooted teeth. It should be realized that during cleaning and shaping procedures, dentine chips, microorganisms, pulpal remnants, irrigating solution, or necrotic debris may be pushed into the periapical region causing inflammation and postoperative pain. ${ }^{5}$

\section{At 1 Week}

Prashant et al demonstrated that the incidence of postobturation pain decreased over time.

Pain levels showed a steady reduction in the following days in both single-visit and multiple-visit groups according to Genet et al. ${ }^{11}$

\section{At 4 and 6 Weeks}

There were no patients who reported with postoperative pain in all the groups.

Edionwe et al in 1998 and Udoye et al in 2004 also reported that the postoperative pain decreased significantly after a period of 1 week and no pain was observed in any patients after 1 week. The results of these studies are in accordance with the results of the present study. ${ }^{12}$

In a study by Bhagwat and Mehta in 2013,single-visit endodontic therapy in teeth with periapical lesion, $16 \%$ had mild pain. The results of the above study is in accordance with the present study; however, 6 patients in Group 2 (single-visit endodontic [SVE] with periapical rarefaction) showed distressing pain. ${ }^{13}$

\section{Swelling after $\mathbf{4 8}$ Hours Postendodontic Therapy}

The high incidence of postoperative swelling in patients can be due to the extension of pulpal disease into the periapical tissues can result in swelling and infection. Generally, the tissue swelling can be seen at the initial emergency visit, at an interappointment flare-up, or as a postendodontic complication.

Preoperatively, swelling was absent in all the teeth included in the present study. Only 1 patient in Group 2 (SVE with periapical rarefaction) and 1 patient in Group 4 reported with swelling after the endodontic treatment.

There was no swelling seen in patients after 1,4 , and 6 weeks postoperatively. This is in accordance with the studies by Prashant et al and Edionwe et al in which no patients reported with any postoperative swelling for both SVE and MVE. ${ }^{3}$

\section{Tenderness after 48 Hours Postendodontic Therapy}

A positive response to percussion, indicating an inflamed periodontal ligament, can be caused by a variety of factors (e.g., teeth undergoing rapid orthodontic movement, recent high restoration, lateral periodontal abscess, and partial or total necrosis of the pulp).

After 1 week, there was a gradual decrease in tenderness to percussion observed in patients of all the groups. There was no tenderness to percussion observed at 4 and 6 weeks in all the groups after the endodontic therapy. This is in accordance to the study by Prashant et al and Edionwe et al who observed no tenderness to percussion after 4 and 6 weeks. ${ }^{12}$

\section{Radiographic Evaluation of Periapical Rarefactions till 18-Month Follow-Up in Groups 2 and 4}

Some patients in both the groups showed uncertain healing, for favorable healing more time is required.

There were no clinical symptoms (pain, tenderness to percussion, and swelling etc.) observed in all the patients, so this radiographic evaluation cannot be associated with the failure of root canal therapy. ${ }^{14}$

According to Prashant et al, however, it is necessary to acknowledge the fact that a period of 6 weeks is too short a period for radiographic evaluation to draw any confirm conclusion regarding the outcome of treatment. The resolution of periapical rarefactions in this study supports the results of the present study. ${ }^{3}$

Sathorn et al reported $100 \%$ success by means of complete resolution of periapical radiolucency and an intact lamina dura after a period of 12 months. ${ }^{15}$

Friedman and Ray observed that the complete reestablishment of normal structure might not occur for all cases under nonsurgical endodontic treatment. Therefore, there is no consensus whether complete periapical healing is a must in the success of endodontic treatment. Wong et al questioned the persistent apical radiolucency over 20 years as absolute failure. ${ }^{14}$

In the current study, postoperative complications like pain, tenderness to percussion, and swelling at 6-week follow-up, and radiographic changes after 18 months follow-up were assessed.

\section{Conclusion}

All the groups showed statistically no significant differences between them. The patients either treated in single-visit or multiple-visit showed no significant postoperative complications after the treatment. Patients in Group 3 (MVE without periapical rarefactions) showed the best results among all the other groups.

\section{Conflict of Interest}

None declared.

\section{References}

1 Patil AA, Joshi SB, Bhagwat SV, Patil SA. Incidence of postoperative pain after single visit and two visit root canal therapy: A randomized controlled trial. J Clin Diagn Res 2016;10(5):ZC09-ZC12

2 Tarale K. Post-operative pain analysis between single visit and two visit root canal treatments using visual analogue scale: an in vivo study. Journal of Dental \& Allied Sciences. 2013;2(1):8-15

3 Prashanth MB, Tavane PN, Abraham S, Chacko L. Comparative evaluation of pain, tenderness and swelling followed by radiographic evaluation of periapical changes at various intervals of time following single and multiple visit endodontic therapy: an in vivo study. J Contemp Dent Pract 2011;12(3):187-191 
4 Peters LB, Wesselink PR. Periapical healing of endodontically treated teeth in one and two visits obturated in the presence orabsence of detectable microorganisms. Int Endod J 2002;35:660-667

5 Fava LR. One-appointment root canal treatment: Incidence of postoperative pain using a modified double-flared technique. Int Endod J 1991;24(5):258-262

6 Kvist T, Molander A, Dahlén G, Reit C. Microbiological evaluation of one- and two-visit endodontic treatment of teeth with apical periodontitis: a randomized, clinical trial. J Endod 2004;30(8):572-576

7 Yilmaz Z, Ozdemir HO, Gorduysus O. Evaluation of single and multiple visit root canal therapy a randomized clinical cases. Clinical Dentistry and Research 2012;36(3):59-63

8 Fava LRG. A clinical evaluation of one and two-appointment root canal therapy using calcium hydroxide. Int Endod J 1994;27(1):47-51

9 Singla R, Marwah N, Dutta S. Single versus multiple-visit root canal treatment. Int J Clin Pediatr Dent 2008;1(1):17-24
10 Molander A, Warfvinge J, Reit C, Kvist T. Clinical and radiographic evaluation of one- and two-visit endodontic treatment of asymptomatic necrotic teeth with apical periodontitis: a randomized clinical trial. J Endod 2007;33(10):1145-1148

11 Genet JM, Wesselink PR, Thoden van Velzen SK. The incidence of preoperative and postoperative pain in endodontic therapy. Int Endod J 1986;19(5):221-229

12 Edionwe JI, Shaba OP, Umesi DC. Single visit root canal treatment:a prospective study.NigerJClin Pract 2014;17(3):276-281

13 Bhagwat S, Mehta D. Incidence of post-operative pain following single visit endodontics in vital and non-vital teeth: An in vivo study. Contemp Clin Dent 2013;4(3):295-302

14 Wong AWY, Tsang CS, Zhang S, et al. Treatment outcomes of single-visit vs. multiple-visit non-surgical endodontic therapy: a randomized clinical trial. BMC Oral Health 2015;15:1-11

15 Sathorn C, Parashos P, Messer H. Australian endodontists' perceptions of single and multiple visit root canal treatment. Int Endod J 2009;42(9):811-818 